\title{
Brief, Written Reflections Improve Interest of Introductory Animal Science Undergraduates
}

\author{
MaryGrace Erickson, ${ }^{\dagger}$ Michel A. Wattiaux, ${ }^{\dagger}$ Danielle Marks, ${ }^{\dagger}$ \\ and Elizabeth L. Karcher** \\ 'Department of Animal \& Dairy Sciences, University of Wisconsin-Madison, Madison, WI 53703; \\ ःDepartment of Animal Sciences, Purdue University, West Lafayette, IN 47907
}

\begin{abstract}
In addition to stimulating interest through experiential means, educators can support interest development through structured reflection. Our randomized controlled intervention study assessed the effectiveness of 10-minute written utility-value reflections designed to enhance the interest of introductory animal science students. During the Spring 2019 semester, we randomly assigned participating students into two blocks, utility-value reflection $(n=39)$ and control $(n=34)$, at the beginning of the course. In week 6 during the 16-week semester, students completed corresponding tasks: either written reflections on the personal value of course laboratory material or a control picture-summarization task. Results showed that the utility-value reflection intervention tended to improve situational interest and was most effective for students with low pretest individual interest. Neither the intervention nor the interest variable predicted course performance. In utility-value reflection responses, we catalogued themes aligned with a range of task-value components beyond utility-value. Our results reinforce previous work indicating that utility-value reflections support low individual interest students in developing academic motivation.
\end{abstract}

\section{INTRODUCTION}

Interest is obtained not by thinking about it and consciously aiming at it, but by considering and aiming at the conditions that lie back of it, and compel it. (Dewey, 1913, pp. 95)

Most college educators can speak at length on the benefits of having interested students (Ulriksen, 2009; Wong and Chiu, 2018). Indeed, research has shown that interested students tend to be more attentive, persistent, and effortful in the classroom (Hidi and Renninger, 2006) and that interest significantly correlates with academic performance and deep learning (Alexander, 1997; Schiefele et al., 1992). Still, in "hard applied" disciplines such as animal science, many educators struggle to leverage interest effectively (Becher, 1987, p. 289; Hidi and Harackiewicz, 2000). Among these teachers, there is widespread belief that interest is something permanent that students either have or do not have (Hidi and Renninger, 2006). Recently, however, experimental studies on interest (hereafter termed "intervention studies") have proliferatedoffering compelling evidence that educators in hard science disciplines can impact interest development through even minor actions in the classroom, particularly when initial interest is low (Harackiewicz et al., 2016; Rosenzweig and Wigfield, 2016).

Colloquially, "interest" refers to feelings of curiosity, engagement, and excitement. In psychology, theorists have described interest as a motivational process that emerges from dynamic person-environment interactions and has both affective and evaluative components (Izard, 2007; Schiefele, 2009). According to the four-phase model of interest development, interest occurs in several distinct forms. The most immediate, contextualized form of interest is situational interest, which occurs when features of the environment trigger heightened attention or affect toward an object or topic. Over
Sarah L. Eddy, Monitoring Editor Submitted Aug 4, 2020; Revised Mar 11, 2021; Accepted Apr 1, 2021

CBE Life Sci Educ June 1, 2021 20:ar28

DOI:10.1187/cbe.20-08-0164

*Address correspondence to: Elizabeth L. Karcher (ekarcher@purdue.edu).

(c) 2021 M. G. Erickson et al. CBE-Life Sciences Education @ 2021 The American Society for Cell Biology. This article is distributed by The American Society for Cell Biology under license from the author(s). It is available to the public under an Attribution-Noncommercial-Share Alike 3.0 Unported Creative Commons License (http://creativecommons.org/licenses/ by-nc-sa/3.0)

"ASCB®" and "The American Society for Cell Biology ${ }^{\circledR}$ " are registered trademarks of The American Society for Cell Biology. 
time, interest can develop into a more stable, trait-like disposition referred to as individual interest. This represents crystallization of interest as an aspect of identity and personality-the predisposition to re-engage with particular material over time (Hidi and Renninger, 2006). The two forms of interest are distinct, but often coincide (Hidi and Renninger, 2006).

The unique features of interest make it possible to employ a variety of interest-enhancing interventions in educational settings. For example, in past efforts, we attempted to improve animal science students' interest by altering experiential characteristics of educational activities (Erickson et al., 2019). Like others, we documented that active-learning modalities such as hands-on or problem-based learning produced higher levels of situational interest for our students (Schraw and Lehman, 2001; Erickson et al., 2020a). In theory, these richer, more realistic, more personalized learning experiences stimulated greater interest in our students by intersecting in broader, deeper ways with learners' ongoing affective, cognitive, sensorimotor, and psychosocial processes (Marton and Säljö, 1976; Jarvis, 2004; Izard, 2007).

In addition to shaping learning experiences, educators also affect interest development by guiding learners' processes of reflection. As learners reflect, they consolidate experiences into internalized value and meanings (Kolb, 1984). In the current study, we build on appraisal, functionalist, and dynamic systems theories of emotion, which suggest that interest emerges as learners interpret their experiences within complex personal frameworks (e.g., appraisals, values, goals, instrumental actions; Lewis and Granic, 2000; Witherington and Crichton, 2007) amid social forces (Markus and Kitayama, 1994). We assume that reflection, as a metacognitive meaning- and sense-making process, influences interest development by altering individuals' subjective task value (Eccles and Wigfield, 2002; Sandars, 2009).

\section{Expectancy-Value Theory}

Interventions that manipulate interest by enhancing subjective task value are rooted in expectancy-value theory (EVT) of achievement motivation (Eccles and Wigfield, 2002). EVT proposes that an individual's motivation is determined by the expectancies (beliefs about outcomes of particular tasks) and subjective values (usefulness, enjoyment, importance) that individual ascribes to particular tasks. A great deal of research describes the importance of expectancies in motivation (for a review, see Pintrich and Schunk, 1996). Task value, on the other hand, has only recently captured the attention of educational researchers. Due to its considerable conceptual overlap with interest, task-value research has grown substantially alongside developments in interest theory and nationwide efforts toward student-centered, interest-driven learning. Conceptually, task value comprises four components, each of which contributes to the experience of situational interest and the development of individual interest: 1) attainment value, the personal significance of doing well; 2) intrinsic value, the amount of enjoyment the individual derives from the task; 3) utility value, how the task relates to future goals; and 4) costs, what the individual has to give up to accomplish the task (Eccles and Wigfield, 2002). The first three components interact to contribute positively to interest development, while perceived costs can detract (Flake et al., 2015).

\section{Improving Interest through Reflection-Based Interventions}

Reflection-based interest interventions typically aim to communicate the value of course material to participants-encouraging them to internalize it as meaningful (Rosenzweig and Wigfield, 2016). Researchers have attempted a variety of interventions, differing on several levels.

First, communicating value can occur through direct testimony (i.e., a teacher or older student shares why the material is relevant) or through prompts that encourage students to self-generate task-value messages (Durik et al., 2015a). Directly communicating value appears to increase interest for certain students but can undermine interest for low-performing or low-expectancy students (Durik et al., 2015b). Conversely, student-centered messages appear to have consistently positive or achievement gap-closing effects (Harackiewicz et al., 2016).

Second, interest interventions differ in their targeted motivational outcomes. While some researchers fix attention on specific components of task value (e.g., utility value; Hulleman et al., 2010; Brown et al., 2015), others consider a combination of utility, attainment, and intrinsic values (e.g., Acee and Weinstein, 2010). Indeed, although attainment-, utility-, and intrinsic-value attributes of task value are conceptually distinct, they are often positively correlated (Eccles and Wigfield, 1995). Previous attempts to manipulate a single component (utility value) have ultimately affected other aspects of task value and expectancies (Hulleman et al., 2017; Priniski et al., 2018).

Finally, interventions differ in intensity and duration. Researchers have enhanced interest with interventions as short and simple as two writing tasks for students (Hulleman et al., 2010) or as involved as a 2-year, multiplatform, two-generation intervention (Harackiewicz et al., 2012). The optimal dosage and intensity depend on desired outcomes and student and classroom characteristics (Canning et al., 2018). However, researchers have recently focused efforts on 1) testing and refining broadly applicable interventions requiring low input from instructors and 2) developing understanding of intervention functioning specific to certain instructional contexts.

\section{PURPOSE AND OBJECTIVES}

Our randomized controlled intervention study sought to empirically test the effects of a brief written utility-value reflection intervention, conducted at four time points throughout the semester, on the situational interest of introductory animal science students. The following objectives guided our research:

1. Qualitatively explore task-value themes produced by the utility-value reflection group.

2. Test the effectiveness of a reflection-based utility-value intervention throughout the semester for students with varying levels of pretest individual interest.

3. Evaluate the relationships among treatment condition, pretest and post-test individual interest, average situational interest during the semester, and course performance.

\section{METHODS}

\section{Context and Participants}

We conducted our experiment during the Spring 2019 semester of an Introduction to Animal Agriculture course. This 16-week course is a medium-enrollment ( $\sim 90-110$ students) introductory 
TABLE 1. Schedule of experimental procedures

\begin{tabular}{|c|c|c|c|}
\hline Week $^{\mathrm{a}}$ & Treat. $^{b}$ & Survey & Objective \\
\hline \multicolumn{4}{|l|}{1} \\
\hline 2 & & $\mathrm{X}$ & Test preclass individual interest, verify covariate balance across treatment and control groups \\
\hline \multicolumn{4}{|l|}{3} \\
\hline \multicolumn{4}{|l|}{4} \\
\hline 5 & $\mathrm{X}$ & & \\
\hline 6 & $\mathrm{X}$ & $\mathrm{X}$ & Test situational interest, validate treatment administration \\
\hline 7 & $\mathrm{X}$ & $\mathrm{X}$ & Test situational interest, validate treatment administration \\
\hline \multicolumn{4}{|l|}{8} \\
\hline 9 & $\mathrm{X}$ & & \\
\hline \multicolumn{4}{|l|}{10} \\
\hline \multicolumn{4}{|l|}{11} \\
\hline 12 & $\mathrm{X}$ & $\mathrm{X}$ & Test situational interest, validate treatment administration \\
\hline 13 & $\mathrm{X}$ & & \\
\hline \multicolumn{4}{|l|}{14} \\
\hline 15 & & $\mathrm{X}$ & Test long-term effects of interventions on situational interest and individual interest \\
\hline 16 & & & \\
\hline
\end{tabular}

course typically consisting primarily of first-year and pre-veterinary students with relatively little experience in animal agriculture (Erickson et al., 2019). The course comprises twice-weekly 50-minute lectures and a weekly 110-minute laboratory session. All experimental procedures took place during course laboratories.

The lead instructor for the course taught course lectures using a PowerPoint-based interactive lecture approach (Bernstein, 2018). One undergraduate teaching assistant (TA) assisted the lead instructor in lecture instruction and administrative tasks. A graduate laboratory coordinator and a total of 11 undergraduate TAs (two to three per laboratory section) facilitated the course's five laboratory sessions. The laboratory coordinator and laboratory TAs carried out experimental procedures for this study. The Institutional Review Board approved all study procedures.

\section{Study Design}

Table 1 summarizes the schedule of experimental procedures, and response rates across experimental periods are shown in Table 2. The experimental sample consisted of 73 students who completed both the pre- and posttests. Of 100 total students in the course at the beginning of the semester, we enrolled a subset $(n=91)$ in our study via a pre survey. Eight students missed the pre survey or opted out of participation, and one student dropped the course. The responses of 18 additional students who did not complete the post survey were excluded.
We assigned each student to a unique treatment group for the duration of the study: either the control picture-summarization group (CTRL) or the utility-value reflection group (UVR). To assign treatments, we used block randomization to ensure equal sample sizes and reduce the potential for error in administering the intervention and control conditions (Suresh, 2011). Before the first laboratory sessions, we randomized students in each laboratory section into four blocks, consisting of four to six students each, for a total of 20 blocks. For each laboratory section, we randomly selected two blocks and assigned them to the intervention condition. Students in the remaining two blocks served as that laboratory section's control group. We repeated this procedure for each of the course's five laboratory sections. Before experimental analysis, we used chi-squared and Welch's two-sample $t$ tests to verify successful randomization, that is, no significant differences existed between control and intervention groups for baseline covariates (Table 3). Pretest individual interest and frequencies of females and underrepresented minorities did not differ between CTRL and UVR groups. However, a significant chi-squared test indicated that first-generation college attendance was non-independent from the treatment condition.

Students completed a pre survey assessing demographics and baseline situational and individual interest. Then, they completed the intervention or control activities in six nonconsecutive weeks during the semester, during which time they intermittently completed surveys on their situational interest

TABLE 2. Response rates for control and utility-value reflection groups across four experimental time points

\begin{tabular}{|c|c|c|c|c|c|}
\hline Survey & Week & $\operatorname{UVR}(n)$ & CTRL (n) & Total $(n)$ & Total $(\%)^{\mathrm{a}}$ \\
\hline Pre & 1 & 39 & 34 & 73 & 100.0 \\
\hline Period 1 & 6 & 36 & 28 & 64 & 87.7 \\
\hline Period 2 & 7 & 36 & 35 & 71 & 97.3 \\
\hline Period 3 & 12 & 36 & 33 & 69 & 94.5 \\
\hline Period 4/Post & 15 & 39 & 34 & 73 & 100.0 \\
\hline
\end{tabular}

${ }^{a}$ Response rates presented as a percentage of the post survey respondents. 
TABLE 3. Demographic information of control and utility-value intervention groups with chi-squared and Welch's two-sample $t$ tests for independence from the treatment condition $(N=73)$

\begin{tabular}{|c|c|c|c|c|c|c|}
\hline Parameter & UVR & CTRL & $\chi^{2}$ & $t$ & $d f$ & $p$ \\
\hline \multicolumn{7}{|l|}{ Pretest } \\
\hline 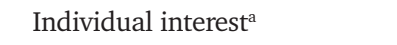 & $6.1(0.8)$ & $6.3(0.7)$ & & 0.9 & 70.4 & 0.36 \\
\hline \multicolumn{7}{|l|}{ Early performance } \\
\hline First exam & $73.8(9.5)$ & $76.8(11.8)$ & & 1.2 & 63.3 & 0.25 \\
\hline First 5 lab quizzes & $8.3(0.8)$ & $8.2(0.9)$ & & -0.4 & 66.9 & 0.72 \\
\hline \multicolumn{7}{|l|}{ Period 4/posttest } \\
\hline Female & $31(79.5 \%)$ & $25(73.5 \%)$ & 0.1 & & 1 & 0.75 \\
\hline Underrepresented minority ${ }^{\mathrm{b}}$ & $5(12.8 \%)$ & $7(20.6 \%)$ & 0.3 & & 1 & 0.56 \\
\hline First generation 4-year degree & $50(34.0 \%)$ & $24(18.5 \%)$ & 1.6 & & 1 & 0.21 \\
\hline Parents' highest education ${ }^{c}$ & Bachelor's & Bachelor's & & & & \\
\hline
\end{tabular}

aPretest individual interest is an average of responses to eight items on a 1 to 7 Likert scale.

bBased on the U.S. Census Bureau definition, we considered students selecting any the following options as their dominant racial/ethnic identity as underrepresented minorities: Black or African American, Hispanic or Latino, American Indian or Alaska Native, or Asian.

'Mode of options high school diploma or equivalency, associate's degree, bachelor's degree, master's degree, doctorate or professional degree, none of the above.

and to validate correct treatment administration. Finally, students completed a posttest on situational and individual interest at the end of the semester. Students received extra credit for participation in surveys and laboratory participation points for completing written activities.

\section{Utility-Value Reflection Intervention}

For both UVR and CTRL treatment groups, we used written prompts to guide students in brief, 10-minute writing activities (Table 4). The UVR group prompts were based on the utility-value prompts developed by Hulleman et al. (2010) and were intended to stimulate reflection on the material's utility value. Conversely, the CTRL group completed a picture-summarization task intended to bring the material to mind for a rote purpose without prompting reflective meaning-making.

Although the UVR prompts were intended to target utility value, two manipulation checks indicated that additional components of task value were reflected in students' experiences with the intervention. First, one researcher (M.G.E.) read through student responses, noting a substantial focus on the intrinsic value of material. Second, we quantitatively assessed utility value following an initial test of the intervention, using a three-item scale developed by Hulleman et al. (2010). We were unable to differentiate between CTRL and UVR groups on the basis of utility-value ratings, and the scale was not internally consistent with our group. The lack of specificity to utility value may be due to its strong correlations with other aspects of task value and is consistent with other utility-value intervention studies (Priniski et al., 2019).

\section{Instrumentation}

To measure situational and individual interest, we selected questionnaires conceptually aligned with our operationalization of interest development as an active, relational process organizable into phases and influenced both by experiences and reflective appraisals: Linnenbrink-Garcia and colleagues' (2010) Situational Interest Questionnaire and Individual Interest Questionnaire. We adapted wording to make items specific to our context. For situational interest, items reflect the Introduction to Animal Agriculture class (e.g., "My ANSC 102 class is exciting"). For individual interest, items refer to animal sciences as a discipline (e.g., "Animal sciences is practical for me to know").

We assessed reliability during the initial experimental period. Our modified individual and situational interest questionnaires demonstrated excellent reliability, with standardized Cronbach's $\alpha$ coefficients of 0.96 and 0.97 , respectively. To validate that students had completed the treatment intended (i.e., that no student had switched groups and/or received the wrong activity), we had students input an identifier from their written assignment in their online survey at three time points (weeks 6, 7, and 12). Results verified that $100 \%$ of students received the correct treatment during all three intervention days.

Course instructors provided grades on a percentage basis at the end of the semester. Grading was criterion based and consistent across laboratory sections. We assessed course performance using final course grades $(\mathrm{M}=86.7, \mathrm{SD}=6.7)$ and students' average scores on weekly laboratory quizzes $(M=7.9, S D$ $=1.0)$. We used scores on the first exam $(M=75.2, S D=10.7)$ and the first five laboratory quizzes $(\mathrm{M}=8.3, \mathrm{SD}=0.8)$ to control for early-semester performance. Exam and course grades are shown on a percentage basis, while laboratory quiz scores are presented out of 10 possible points.

\section{Experimental Procedures}

For collection of data for weeks 6, 7, and 12-the validation time points—students began the laboratory by completing

TABLE 4. Brief descriptions of utility-value reflection and control conditions adapted from Hulleman et al. (2010)

\begin{tabular}{lr}
\hline UVR & CRTL \\
\hline Learners given prompt: Write a short 1-3 paragraph essay ( $5+$ sentences & Learners given prompt: Write a short $1-3$ paragraph essay \\
per paragraph) describing the potential relevance of this material to & (5+ sentences per paragraph) on the objects you see in the \\
$\begin{array}{l}\text { your own life or to the lives of other people. Please focus on how this } \\
\text { technique could be useful to you or other people and give examples. }\end{array}$ & pictures. Describe in detail the objects you see in front of you. \\
\hline
\end{tabular}




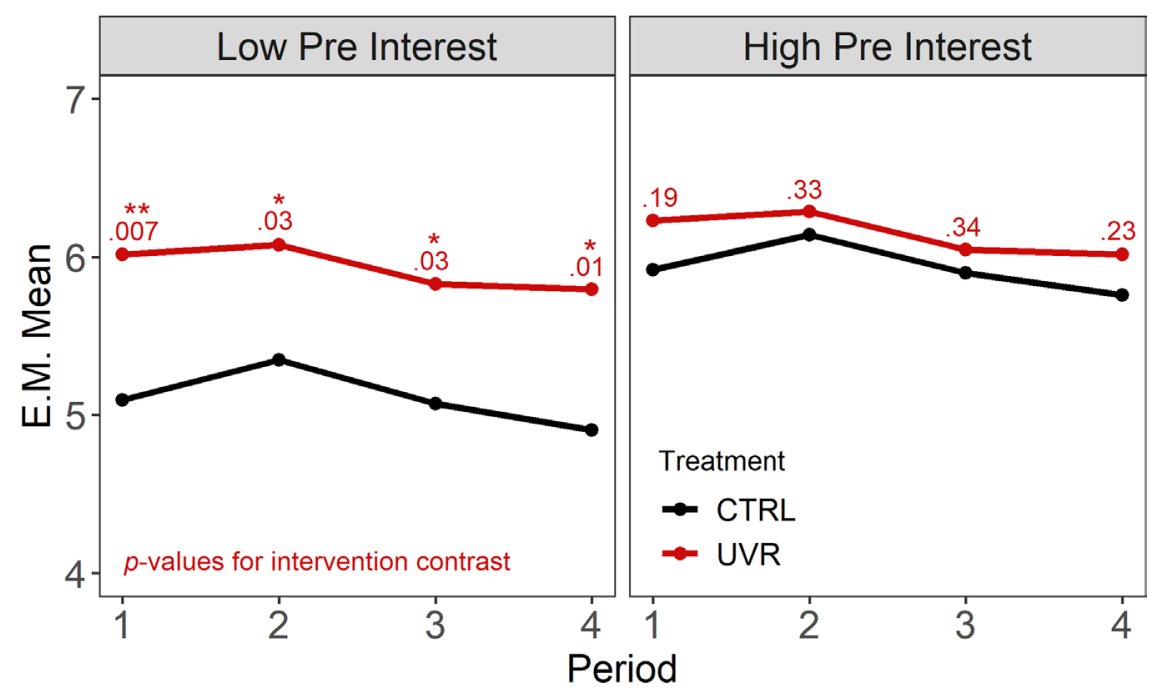

FIGURE 1. Estimated marginal means (E.M. Mean) and standard errors for situational interest for control (CTRL) and utility-value intervention (UVR) groups conditioned on low and high pretest individual interest. Pretest individual interest was trichotomized at thresholds of 6.0 and 6.6 based on a scale of $1=$ low to $7=$ high. The four experimental periods represent weeks $6,7,12$, and 15 of the 16-week semester. Situational interest is expressed on the original scale $(1=$ low to $7=$ high). Significant one-sided post hoc Tukey's tests are denoted with asterisks: ${ }^{*} p<0.05 ;{ }^{* *} p<0.01$.

normal class activities (held constant across groups). Then, we instructed all students that they would be completing a writing activity before proceeding. We divided students $(n=18$ to 25 per laboratory section) and seated subgroups in four separate areas of a large laboratory space. Students in two subgroups received the control activity (CTRL; picture-summarization task) and students in the remaining two subgroups received the intervention (UVR; utility-value reflection). We instructed students that they would have 10 minutes to complete the activity. The course laboratory coordinator and two undergraduate TAs monitored students during the task and answered clarification questions. The course instructor, the undergraduate TAs, and the students in the course were blind to experimental treatments, which the laboratory coordinator administered for all course sections. After 10 minutes, we instructed students to cease working on the activity and place their work facedown on the table. Then, they scanned a QR code and completed a questionnaire on their laptop or mobile device, using as much time as needed. On weeks 5, 9, and 13, students completed the UVR or CTRL activities during bus rides back from facility tours. Undergraduate TAs supervised students during the process. No questionnaires were administered at these time points. Topics varied from week to week (week 6, goat health; week 7, equine nutrition; week 12, mastitis management; week 13, poultry production).

\section{Statistical Analysis}

We conducted all statistical analyses in R (R Core Team, 2019) declared significance at $p<0.05$ and tendencies at $p<0.10$. To examine situational interest data across the four time points (objective 1), we used restricted maximum likelihood estimation to build linear mixed models (LMMs) using the lme4 package (Bates et al., 2015) and assuming that data were missing at random (Twisk et al., 2013). We centered and scaled all continuous independent variables relative to sample means and applied a Box-Cox transformation to situational interest to correct for nonnormality (Box and Cox, 1964; West et al., 2014). Model results are presented as situational interest squared, while estimated marginal means are backtransformed to the original scale.

We tested several random effects specifications to account for hierarchical nesting. We retained a random intercept for student, but not student section or laboratory group, based on likelihood ratiobased nested model comparisons and Bayesian information criterion. Fixed effects included the pretest individual interest, a dummy-coded intervention contrast ( $1=\mathrm{UVR}, 0=\mathrm{CTRL})$, score on the first exam, score on first five laboratory quizzes, experimental period, and the interactions of the intervention with pretest individual interest and experimental period. We retained nonsignificant fixed effects due to their relevance to our objectives and theoretical importance as predictors. We verified normality of residuals graphically and computed variance inflation factors to check for multicollinearity.

To explore the interaction between the intervention and pretest individual interest, we trichotomized the pretest individual interest variable (thresholds $=6.0,6.6$ ). Gelman and Park (2009) suggested that splitting into three rather than two $n$-tiles preserved more power for post hoc comparisons. We computed estimated marginal means for situational interest conditioned on high, medium, and low pretest individual interest for each treatment using the emmeans package (Lenth, 2019). Because we hypothesized positive associations between the intervention and situational interest, we used one-sided significance tests for post hoc pairwise Tukey's tests (Figure 1).

For examination of objective 2, the relationships among treatment group, pretest individual interest, posttest individual interest, average situational interest during the four experimental periods, average laboratory quiz score, and course grade, we computed Kendall and point-biserial correlations using the correlation package (Makowski et al., 2019; Table 5). We used an average of situational interest across available time points for students missing observations at periods 1,2 , and 3.

\section{Qualitative Analysis}

Our qualitative analysis involved a two-part examination of student responses to treatment prompts: 1) examining themes in utility-value responses (objective 3 ) and checking theoretical validity and 2) checking the validity of the control condition. To prevent confounding, we performed all qualitative analyses after the conclusion of quantitative experimentation.

To conduct an additional manipulation check and explore for common themes, we analyzed intervention group responses to all six utility-value prompts using template analysis (Brooks et al., 2015). Template analysis permitted us to define a priori 
TABLE 5. Themes discovered in utility-value reflection responses and representative quotes, categorized within task-value components

\begin{tabular}{|c|c|}
\hline \multicolumn{2}{|l|}{ Utility value } \\
\hline Career plans & "As a food scientist, I would need to understand the production side of animal products." \\
\hline Academic plans & "I will eventually have to take ANSC 221 and I feel this information will be helpful." \\
\hline Hobbies or future hobbies & "I want to raise rabbits and goats in the future." \\
\hline Altruism & "If I go on a mission trip this could help me determine if the dairy in that area is safe to consume." \\
\hline Family/friends & "I have family that has horses. Therefore if they ever need my help I will know what to do." \\
\hline Not valuable based on career plans & "I do not think I will have any relationship to this industry in my professional life." \\
\hline & "Seeing the different caging systems definitely fascinated me." \\
\hline Meaningful past experiences & $\begin{array}{l}\text { "I grew up raising horses and helping my grandpa feed, wash, brush, and other horse } \\
\text { maintenance." }\end{array}$ \\
\hline \multicolumn{2}{|l|}{ Attainment value } \\
\hline Idealized self & "This information will help me to be the best student and future vet possible." \\
\hline Obligation to advocate/represent agriculture & $\begin{array}{l}\text { "I want to have a well-rounded knowledge about all things agriculture [sic] so that I can teach } \\
\text { people about all the good things that agriculturalists do." }\end{array}$ \\
\hline
\end{tabular}

categories based on Eccles and Wigfield's (1995) conceptualization of task value. We applied standard template analysis procedures consisting of several steps to our data. First, one of the researchers (M.G.E.) familiarized themselves with the data by reading and rereading responses and noting initial codes. Then, she developed a preliminary list of codes and began searching for meaningful clusters, mapping the codes hierarchically into themes. Then, she grouped themes into categories based on the a priori theoretical framing and selected representative quotes. Finally, she reviewed themes against the extracted codes and the original data set, checking for consistency (Braun and Clarke, 2006).

To verify that the picture-summarization task (CTRL) functioned as intended and that student responses were distinct from responses to the utility-value prompts, we used a deductive, rapid analysis approach using the task-value codes as a predefined contrast (Taylor et al., 2018). A researcher first spent approximately 1 hour looking through control task responses and noting any key issues (i.e., responses appearing to use taskvalue language). Then, the researcher used a preprepared summary template to sort out acceptable and questionable responses to picture-summarization prompts, noting the respective fractions in each category.

Our research employed several measures to ensure qualitative trustworthiness. To ensure credibility, we grounded our research in well-established theories, used widely accepted methods, and examined our results in light of previous findings (Shenton, 2004). To establish dependability and transferability, we provide detailed methodological description, including important pieces of our reflective commentary throughout the research process. Additional strategies for trustworthiness included early familiarity with the culture of participants and tactics to ensure their honesty in surveys. The analysis of our study employed peer scrutiny and negative case analysis to enhance trustworthiness of conclusions (Silverman, 2001).

\section{RESULTS}

\section{Demographics}

Table 3 summarizes demographic information of CTRL and UVR groups, showing no significant differences between treatment groups for each of the observed baseline covariates. On average, our participants reported high individual interest in the subject at both the start and end of the semester. Although posttest individual interest was numerically lesser $(M=6.12$, $\mathrm{SD}=1.04)$ than pretest individual interest $(\mathrm{M}=6.21, \mathrm{SD}=$ 0.74), a paired $t$ test indicated no significant differences between mean individual interest in the pre- and posttests; $t(72)=0.75, p=0.46$. The majority of our participants were female, white, and not first-generation college attendees.

\section{Themes in Articulated Task Value}

Table 5 summarizes all student responses to six utility-value prompts throughout the semester. Although the reflection prompts were based on utility value, we noted a significant focus on intrinsic and attainment value when examining codes using these a priori themes. Students appeared to derive diverse meanings from their experiences. Only a small fraction of responses $(<5 \%)$ contained statements communicating a lack of perceived value. In some cases, students indicated that they failed to see a connection between the material and their career plans. Our introductory animal agriculture course covers a range of topics across species and production systems, so it is plausible that some labs may be more difficult for certain students to connect with. In other cases, students mentioned perceived costs-another important component of task value (e.g., "I have so much respect for the amount of attention and care ... I am just realizing [the] production side isn't for me"). In most cases, responses containing negative task-value phrases also contained positive messages, indicating that the student had successfully made some connections with material. Therefore, the intervention appears to have functioned to 
TABLE 6. Linear mixed model describing situational interest across four experimental periods

\begin{tabular}{lcr}
\hline & \multicolumn{2}{c}{ Situational interest $^{\mathrm{a}}$} \\
\cline { 2 - 3 } Predictors & Estimates & \multicolumn{1}{c}{$\boldsymbol{p}$} \\
\hline (Intercept) & 31.0 & $0<0.001$ \\
Pretest individual interest & 5.9 & $0<0.001$ \\
Score on first exam & 0.1 & 0.97 \\
Score on first five lab quizzes & 0.5 & 0.72 \\
First-generation & 1.3 & 0.64 \\
Female & 1.4 & 0.64 \\
Underrepresented minority & -0.5 & 0.89 \\
Utility-value reflection (UVR) & 5.3 & 0.06 \\
Period 2 & 3.1 & 0.09 \\
Period 3 & 0.2 & 0.92 \\
Period 4 & -1.6 & 0.40 \\
UVR * pretest individual interest & -4.9 & 0.05 \\
UVR * period 2 & -2.2 & 0.38 \\
UVR * period 3 & -2.2 & 0.38 \\
UVR * period 4 & -0.9 & 0.72 \\
Random effects & & \\
$\sigma^{\mathrm{b}}$ & & \\
$\tau_{\text {o0 student }}$ & 51.0 & \\
ICC $_{\text {student }}$ & 72.7 & \\
$N_{\text {student }}$ & 0.59 & \\
Observations $_{\text {Marginal }{ }^{2}}$ & 73 & \\
Conditional R $^{2}$ & 277 & \\
\hline
\end{tabular}

${ }^{\mathrm{a} C o e f f i c i e n t s ~ r e p r e s e n t ~ s i t u a t i o n a l ~ i n t e r e s t ~ s q u a r e d, ~ t r a n s f o r m e d ~ f r o m ~ a ~ s c a l e ~ f r o m ~}$ 1 (low) to 7 (high).

${ }^{b}$ The $\sigma^{2}$ and $\tau_{00}$ represent the within-group and between-group variance, respectively. ICC ${ }_{\text {student }}$ shows the intraclass correlation coefficient for the random intercept of student.

create utility value-enhancing messages as intended, in addition to creating messages related to other task-value components. The control picture-summarization prompt also appeared functional in our sample. During rapid analysis, less than $10 \%$ of written responses surfaced as questionable (i.e., possibly overlapping with task-value responses). These results demonstrate successful implementation of both control and utility-value conditions.

\section{Situational Interest across the Semester}

Table 6 presents an LMM describing situational interest across the semester. Across experimental time points, situational interest was significantly, positively predicted by pretest individual interest. Course performance before experimentation (average score on first five lab quizzes, first exam score) was unrelated to situational interest. Situational interest did not differ significantly based on experimental periods relative to the reference period, period 1 . The utility-value reflection tended to improve situational interest. No treatment by period interactions significantly predicted situational interest. However, a treatment by pre-individual interest interaction tended toward significant. The marginal coefficient of determination indicated that the fixed effects explained $15 \%$ of the variation in situational interest. The intraclass correlation coefficient showed that within-student variation accounted for $65 \%$ of total variation, showing consistency within individuals over time.
Figure 1 illustrates estimated marginal mean situational interest in the control and intervention groups throughout the semester expressed on original scale, conditioned on low and high pretest individual interest. We observed no significant differences between CTRL and UVR groups for the four experimental time points in the high pretest individual interest group or the medium pretest interest group ( $p=0.43$ to 0.65 ). In contrast, pairwise comparisons of UVR and CTRL within the low-pretest individual interest group showed a significant positive effect of UVR across all four experimental periods.

\section{Relationships among UVR Intervention, Interest Variables, and Course Performance}

Table 7 shows correlations among measured variables. We discovered no statistically significant pairwise associations between average situational interest during the semester and course performance variables. However, all course performance variables were positively correlated. Pre- and posttest individual interest showed a strong positive correlation. Average situational interest during the semester had a strong positive relationship with posttest individual interest, but not pretest individual interest. The intervention contrast was unrelated to course performance and interest variables.

\section{DISCUSSION}

Our randomized controlled study evaluated the effects of a brief, reflection-based utility-value intervention on the situational interest and course performance of students in an introductory animal agriculture course laboratory. Our quantitative results showed promise that utility-value interventions can produce deep reflection and may enhance situational interest. Our qualitative analysis illuminated a multitude of task-valuing dimensions along which students connected learned material to their lives in response to utility-value prompts. In sum, our research confirmed that a self-generated utility-value intervention can improve situational interest in introductory animal sciences students. However, it raised additional questions on intervention design and logistics to maximize effectiveness given student and classroom characteristics.

Our analysis of responses to utility-value prompts revealed diverse interpretations of the purpose and significance of course material, illustrating the value of allowing students to self-generate task-value messages through reflection. Consistent with Harackiewicz et al. (2016), we discovered plentiful references to self, family, friends, and social processes. We were also able to draw gross distinctions between control and utility-value responses qualitatively, although we did not conduct in-depth coding or linguistic analysis. Past research has documented significant differences between responses to control and utility-value prompts in a number of regards. Harackiewicz et al. (2016) noted greater use of language suggesting cognitive engagement and insight in utility-value responses relative to the control task of summarization. Beigman Klebanov et al. (2018) replicated and extended these findings using natural language processing, demonstrating that utility value-prompted writing further produced greater use of argumentative and narrative language. Overall, utility-value interventions in our study and in others seem to enhance engagement in reflective meaning-making processes (Johnson and Sinatra, 2013). However, more research is needed to understand the empirical distinctions 
TABLE 7. Kendall and point-biserial correlations among treatment, interest variables, and course performance $(N=73$ students)

\begin{tabular}{|c|c|c|c|c|c|c|c|c|c|}
\hline & Parameter & 1 & 2 & 3 & 4 & 5 & 6 & 7 & 8 \\
\hline 1 & UVR & 1 & 0.15 & $0-0.11$ & 0.10 & $0-0.07$ & $0-0.02$ & 0.04 & $0-0.14$ \\
\hline 2 & Situational interest ${ }^{\mathrm{a}}$ & & 1 & 0.10 & $0.49 * *$ & 0.02 & $0-0.03$ & 0.01 & $0-0.03$ \\
\hline 3 & Pretest individual interest & & & 1 & $0.34^{*}$ & 0.18 & 0.18 & 0.10 & 0.14 \\
\hline 4 & Posttest individual interest & & & & 1 & 0.11 & 0.11 & 0.11 & 0.07 \\
\hline 5 & Overall course grade & & & & & 1 & $0.68 * *$ & $0.47^{* *}$ & $0.64^{* *}$ \\
\hline 6 & Overall lab quiz score & & & & & & 1 & $0.59 * *$ & $0.49 * *$ \\
\hline 7 & Score on first five lab quizzes & & & & & & & 1 & $0.39 * *$ \\
\hline 8 & Score on first exam & & & & & & & & 1 \\
\hline
\end{tabular}

a Situational interest is averaged over four experimental periods.

* $p$ value $<0.01$.

$* * p$ value $<0.001$

between utility-value and other task-value components and reveal the specific values, goals, and needs that motivate particular students and student groups (Harackiewicz et al., 2015; Priniski et al., 2018).

Past research has shown that introductory animal sciences students have high individual interest that remains relatively stable during the semester and moderate to high situational interest levels that vary with educational experiences (Erickson et al., 2019, 2020b). The present study corroborated these findings: individual interest was high at the start and end of the semester and unaffected by the intervention, and situational interest was high throughout the semester but tended to be greater for the UVR group compared with CTRL students. The four-phase model of interest development predicts that greater situational interest could eventually lead to changes in individual interest with repeated or prolonged exposure (Hidi and Renninger, 2006). However, past studies have shown that the timescale for such changes may be longer than a single semester, especially for students starting with high interest (Fryer and Ainley, 2019).

In addition to affecting individual interest development, the high level of interest in our sample may also have dampened the overall effect of the utility-value intervention on situational interest. Indeed, our intervention improved situational interest of students with low pretest individual interest, but it did not alter the situational interest of students with medium or high pretest individual interest. Other authors have documented similar effects. For example, Hulleman et al. (2010) recorded little to no effect of a student-centered utility-value intervention on students with high positive expectancies, a phenomenon often coinciding with high existing individual interest. Our sample also had few first-generation or underrepresented minority students. Harackiewicz et al. (2015) reports that student-centered utility-value interventions tend to be less beneficial to historically privileged college students relative to their disproportionate benefits for students from historically underrepresented groups. Our analysis showed situational interest was not dependent on gender, first-generation status, underrepresented minority status, or early course grades. However, our sample lacked the diversity and size to examine the interactions between the intervention and certain demographic characteristics. Future iterations matching intervention design with student characteristics may improve intervention effectiveness (Priniski et al., 2018).
In contrast with past research describing utility-value interventions with respect to performance gaps (Harackiewicz et al., 2015; Hulleman et al., 2017), our study showed that a utility-value intervention closed a gap in situational interest for students with low pretest individual interest. Although we noted significant positive correlations among all course performance metrics, we found no significant effects of situational interest, individual interest, or the intervention on course grades. These results are both contradicted and supported in previous work. Prior research has firmly established that interest is related to effort, persistence, and the use of metacognitive strategies (McWhaw and Abrami, 2001; Harackiewicz et al., 2016). When manifest (sometimes operationalized as "achievement-related behaviors"), these attributes appear to mediate interest's positive relationship with performance (Chouinard et al., 2007; Rotgans and Schmidt, 2011). However, the predictive value of interest in determining performance is largely dependent on course objectives and grading structure, which can vary greatly in the types of behaviors rewarded (Pintrich and Schrauben, 1992; Schiefele et al., 1992). In theory, interest strongly predicts performance in courses structured to reward deep learning but may not be associated with performance in courses where assessment emphasizes surface-level learning (Harackiewicz et al., 2000). Interventions that successfully enhance interest can therefore have either positive effects or no effects on performance depending on the course (Durik and Harackiewicz, 2007; Hulleman et al., 2010).

Factors related to intervention timing and dosage may also have affected the results we observed. For example, Canning et al. (2018) reported no differences between three doses and a single dose of utility-value essay with respect to course performance and continuation to a second course on the topic. The authors also reported timing effects that interacted with student characteristics, suggesting that intervening at the beginning improved course performance of low-performing students, and intervening near the end of the semester improved continuation of high-performing students. We timed interventions during the middle of the semester (weeks 5 through 13), which may have been suboptimal. Further, unlike Canning et al. (2018), we did not quantify the depth of utility-value reflections throughout the semester or offer feedback to students to enable them to improve their skills at utility-value reflection. Future experimental and quasi-experimental studies assessing factors related to timing, student precourse interest level, and 
articulated task value may clarify optimal conditions for implementation.

Our choice of context-to implement treatments during laboratory sessions rather than course lectures-may also have affected intervention effectiveness in our experiment. Compared with content-focused course lectures, course laboratories offered more diverse constructs, images, and sensations as material for reflection (Marton and Säljö, 1976; Jarvis, 2004). Some students, however, may have found this distracting. Additionally, students completed laboratory activities and experimental reflections in the grouped seating arrangement typical of course labs. Yet we asked students in the intervention group to introspect deeply on the personal meaning of material. Some students may have found that the grouped setting and other perceptual stimuli detracted from their ability to deeply reflect (Bermúdez, 2017). However, this was an important aspect of our experimental design, because it allowed us to constrain the reflection environment and timing for control and intervention groups as constant across students. In the future, educators and researchers might consider relaxing the experimental conditions surrounding reflective activities to allow more natural, autonomous reflection. Preliminary empirical evidence suggests that value interventions incorporating more choice may more successfully enhance task value and subsequent course performance (Priniski et al., 2019; Rosenzweig et al., 2019).

Laboratory topics are another course context factor that may have influenced our results (week 6, goat health; week 7, equine nutrition; week 12, mastitis management; week 13, poultry production). Reiling and colleagues (2003) note substantial variation in introductory animal science students' primary species and topics of interest, suggesting that students with prior agricultural backgrounds are more likely to appreciate animal management topics. Conversely, Lyvers-Peffer (2011) showed that animal science students perceived unfamiliar topics to be particularly valuable and interesting. Our qualitative data produced evidence corroborating both assertions. These results are also consistent with interest literature, which suggests that both prior knowledge and a perceived lack of knowledge act as antecedents of situational interest (Berlyne and Parham, 1968; Rotgans and Schmidt, 2014). We suggest that unexplained variance, particularly during weeks 7 and 12, may be attributable to students' mixed reactions to unfamiliar topics. We did not measure students' familiarity with or interest in lab-specific topics before each laboratory. However, future research may elucidate how these factors mediate the experience and interpretation of interest in animal science laboratories. Such research may assume particular importance as universities struggle to generate interest in food-animal academic study and careers, topics increasingly unfamiliar to the average student (Posey et al., 2012).

\section{Limitations}

Our results are qualified by at least six important limitations. First, our experiment assessed a single iteration of a course using a moderately sized convenience sample of students that lacked diversity in some dimensions. Although this narrow focus allowed us to perform a tightly controlled test and offer an in-depth description of the conditions surrounding experimentation, our results are not generalizable to other courses or other student populations (Borg and Gall, 1989). Following
Shenton (2004), we leave decisions on transferability to the readers of our study, who have deeper knowledge of the areas outside our classroom to which these results may apply. Second, our sample included only those students from whom we had sufficient data. Students who declined to participate, attended the course infrequently, or dropped out of the course are not reflected in results. Third, we documented non-independence between the treatment condition and first-generation college attendance. Given that first-generation college attendance was unrelated to situational interest in our LMM, it is unlikely that imbalance between UVR and CTRL groups significantly affected estimates of treatment effects. Fourth, we did not investigate the longitudinal effects of the intervention, which research suggests may persist or amplify for years following an intervention (Rozek et al., 2017). Colleges of agriculture could consider using routine course assessments to track motivational variables throughout undergraduate degree programs to determine longitudinal effects. Fifth, we assessed only a single aspect of motivation (situational and individual interest), while research suggests that measuring a profile of motivational variables is a finer-grained analysis (e.g., Dietrich et al., 2019; Rosenzweig et al., 2020). Finally, we urge caution in interpreting the magnitude of the intervention's positive effects based on our results. Although our study had sufficient statistical power to confirm our directional hypothesis, it did not afford much precision in estimating the magnitude of effects (Gelman and Carlin, 2014). In addition to meta-analyses, studies with larger samples or crossover designs may generate more precise information regarding the magnitude of intervention effects.

\section{CONCLUSIONS}

Our results offer preliminary evidence that brief, written utility-value activities can prompt reflection on multiple aspects of task value and improve interest in introductory animal sciences students. Our findings replicated previous research on science, technology, engineering, and mathematics utility-value interventions and extended it to the context of animal science. Although animal science students typically have high individual interest and are engaged in highly interesting experiential activities, our findings suggest that they may still benefit from periodic utility-value reflections.

\section{ACKNOWLEDGMENTS}

This work would not have been possible without our dedicated team of undergraduate teaching assistants and the additional support from Emily Taylor. Most importantly, we thank the students in introductory animal science for sharing their time and thoughts with us.

\section{REFERENCES}

Acee, T. W., \& Weinstein, C. E. (2010). Effects of a value-reappraisal intervention on statistics students' motivation and performance. Journal of Experimental Education, 78, 4, 487-512. https://doi.org/10.1080/ 00220970903352753

Alexander, P. A. (1997). Mapping the multidimensional nature of domain learning: The interplay of cognitive, motivational, and strategic forces. In Maehr, M. L., \& Pintrich, P. R. (Eds.), Advances in motivation and achievement Vol. 10, (pp. 213-250). Greenwich, CT.

Bates, D., Maechler, M., Bolker, B., \& Walker, S. (2015). Ime4: Linear mixed-effects models using Eigen and S4 (R Package Version 1.1-8). Retrieved March 27, 2020, from http://CRAN.R-project.org/package=lme4 
Becher, T. (1987). The disciplinary shaping of the profession. In Clark, B. R (Ed.), The academic profession: National, disciplinary and institutional settings (pp. 271-303). Oakland, CA: University of California Press.

Beigman Klebanov, B., Priniski, S., Burstein, J., Gyawali, B., Harackiewicz, J., \& Thoman, D. (2018). Utility-value score: A case study in system generalization for writing analytics. Journal of Writing Analytics, 2. Retrieved March 27, 2020, from https://journals.colostate.edu/index.php/analytics/ article/view/225

Berlyne, D. E., \& Parham, L. C. C. (1968). Determinants of subjective novelty. Perception \& Psychophysics, 3(6), 415-423. https://doi.org/10.3758/ BF03205748

Bermúdez, J. P. (2017). Do we reflect while performing skillful actions? Automaticity, Control, and the Perils of Distraction, 30(7), 896-924. https:// doi.org/10.1080/09515089.2017.1325457

Bernstein, D. A. (2018). Does active learning work? A good question, but not the right one. Scholarship of Teaching and Learning in Psychology, 4(4), 290-307. https://doi.org/10.1037/stl0000124

Borg, W. R., \& Gall, M. D. (1989). Educational research. An introduction (5th ed.). London, England: Longman.

Box, G. E. P., \& Cox, D. R. (1964). An analysis of transformations. In Source: Journal of the Royal Statistical Society, $26 . \mathrm{https} / /$ doi. org/10.1111/j.2517-6161.1964.tb00553.x

Braun, V., \& Clarke, V. (2006). Using thematic analysis in psychology. Qualitative Research in Psychology, 3(2), 77-101. https://doi.org/10.1191/1478 088706qp063oa

Brooks, J., McCluskey, S., Turley, E., \& King, N. (2015). The utility of template analysis in qualitative psychology research. Qualitative Research in Psychology, 12(2), 202-222. https://doi.org/10.1080/14780887.2014.955224

Brown, E. R., Smith, J. L., Thoman, D. B., Allen, J. M., \& Muragishi, G. (2015). From bench to bedside: A communal utility value intervention to enhance students' biomedical science motivation. Journal of Educational Psychology, 107(4), 1116-1135. https://doi.org/10.1037/edu0000033

Canning, E. A., Harackiewicz, J. M., Priniski, S. J., Hecht, C. A., Tibbetts, Y., \& Hyde, J. S. (2018). Improving performance and retention in introductory biology with a utility-value intervention. Journal of Educational Psychology, 110(6), 834-849. https://doi.org/10.1037/edu0000244

Chouinard, R., Karsenti, T., \& Roy, N. (2007). Relations among competence beliefs, utility value, achievement goals, and effort in mathematics. British Journal of Educational Psychology, 77(3), 501-517. https://doi. org/10.1348/000709906×133589

Dewey, J. (1913). Riverside educational monographs. Interest and effort in education. Boston, MA: Houghton Mifflin Harcourt Publishing. https:// doi.org/10.1037/14633-000

Dietrich, J., Moeller, J., Guo, J., Viljaranta, J., \& Kracke, B. (2019, July). In-themoment profiles of expectancies, task values, and costs. Frontiers in Psychology, 10, 1662. https://doi.org/10.3389/fpsyg.2019.01662

Durik, A. M., \& Harackiewicz, J. M. (2007). Different strokes for different folks: How individual interest moderates the effects of situational factors on task interest. Journal of Educational Psychology, 99, 597-610. https:// doi.org/10.1037/0022-0663.99.3.597

Durik, A. M., Hulleman, C. S., \& Harackiewicz, J. M. (2015a). One size fits some: Instructional enhancements to promote interest don't work the same for everyone. In Renninger, K. A., Nieswandt, M., \& Hidi, S. (Eds.), Interest in mathematics and science learning (pp. 49-62). Washington, DC: American Educational Research Association. https://doi. org/10.3102/978-0-935302-42-4_3

Durik, A. M., Shechter, O., Noh, M. S., Rozek, C. R., \& Harackiewicz, J. M. (2015b). What if I can't? Perceived competence as a moderator of the effects of utility value information on situational interest and performance. Motivation and Emotion, 39, 104-118. https://doi.org/10.1007/ s11031-014-9419-0

Eccles, J. S., \& Wigfield, A. (1995). In the mind of the actor: The structure of adolescents' achievement task values and expectancy-related beliefs. Personality and Social Psychology Bulletin, 21(3), 215-225. https://doi. org/10.1177/0146167295213003

Eccles, J. S., \& Wigfield, A. (2002). Motivational beliefs, values, and goals. Annual Review of Psychology, 53, 109-132. https://doi.org/10.1146/annurev.psych.53.100901.135153
Erickson, M. G., Guberman, D., Zhu, H., \& Karcher, E. L. (2019). Interest and active learning techniques in an introductory animal sciences course. North American College Teachers of Agriculture Journal, 63, 2. Retrieved April 4 2020, from www.nactateachers.org/index.php/current-issues?start=20

Erickson, M. G., Marks, D., \& Karcher, E. (2020a). Characterizing student engagement with hands-on, problem-based, and lecture activities in an introductory college course. Teaching \& Learning Inquiry, 8(1), 138153. https://doi.org/10.20343/teachlearninqu.8.1.10

Erickson, M. G., Wattiaux, M. A., \& Karcher, E. L. (2020b). Longitudinal measurement invariance and stability of individual interest across a 16-week introductory animal sciences course. Natural Sciences Education, 49(1), e20031. https://doi.org/10.1002/nse2.20031

Flake, J. K., Barron, K. E., Hulleman, C., McCoach, B. D., \& Welsh, M. E. (2015) Measuring cost: The forgotten component of expectancy-value theory. Contemporary Educational Psychology, 41, 232-244. https://doi. org/10.1016/j.cedpsych.2015.03.002

Fryer, L. K., \& Ainley, M. (2019). Supporting interest in a study domain: A longitudinal test of the interplay between interest, utility-value, and competence beliefs. Learning and Instruction, 60, 252-262. https://doi org/10.1016/j.learninstruc.2017.11.002

Gelman, A., \& Carlin, J. (2014). Beyond power calculations: Assessing type S (sign) and type $\mathrm{M}$ (magnitude) errors. Perspectives on Psychological Science, 9(6), 641-651. https://doi.org/10.1177/1745691614551642

Gelman, A., \& Park, D. K. (2009). Splitting a predictor at the upper quarter or third and the lower quarter or third. American Statistician, 63(1), 18. https://doi.org/10.1198/tast.2009.0001

Harackiewicz, J. M., Barron, K. E., Tauer, J. M., Carter, S. M., \& Elliot, A. J. (2000). Short-term and long-term consequences of achievement goals: Predicting interest and performance over time. Journal of Educational Psychology, 92(2), 316-330. https://doi.org/10.1037/00220663.92.2.316

Harackiewicz, J. M., Canning, E. A., Tibbetts, Y., Priniski, S. J., \& Hyde, J. S. (2015). Closing achievement gaps with a utility value intervention: Disentangling race and social class. Journal of Personality and Social Psychology, Advance online publication. https://doi.org/10.1037/pspp0000075

Harackiewicz, J. M., Rozek, C. S., Hulleman, C. S., \& Hyde, J. S. (2012). Helping parents to motivate adolescents in mathematics and science: An experimental test of a utility-value intervention. Psychological Science, 23(8), 899-906. https://doi.org/10.1177/0956797611435530

Harackiewicz, J. M., Smith, J. L., \& Priniski, S. J. (2016). Interest matters. Policy Insights from the Behavioral and Brain Sciences, 3(2), 220-227. https:// doi.org/10.1177/2372732216655542

Hidi, S., \& Harackiewicz, J. M. (2000). Motivating the academically unmotivated: A critical issue for the 21st century. Review of Educational Research, 70(2), 151-179. https://doi.org/10.3102/00346543070002151

Hidi, S., \& Renninger, K. A. (2006). The four-phase model of interest development. Educational Psychologist, 41(2), 111-127. https://doi.org/10.1207/ s15326985ep4102_4

Hulleman, C. S., Godes, O., Hendricks, B., \& Harackiewicz, J. M. (2010). Enhancing interest and performance with a utility value intervention. Journal of Educational Psychology, 102(4), 880-895. https://doi.org/10.1037/ a0019506

Hulleman, C. S., Kosovich, J. J., Barron, K. E., \& Daniel, D. B. (2017). Making connections: Replicating and extending the utility value intervention in the classroom. Journal of Educational Psychology, 109(3), $387-$ 404. https://doi.org/10.1037/edu0000146

Izard, C. E. (2007). Basic emotions, natural kinds, emotion schemas, and a new paradigm. Perspectives on Psychological Science, 2(3), 260280. https://doi.org/10.1111/j.1745-6916.2007.00044.x

Jarvis, P. (2004). Adult and continuing education: Theory and practice (2nd ed.). New York, NY: Routledge.

Johnson, M. L., \& Sinatra, G. M. (2013). Use of task-value instructional inductions for facilitating engagement and conceptual change. Contemporary Educational Psychology, 38(1), 51-63. https://doi.org/10.1016/j.cedpsych.2012.09.003

Kolb, D. A. (1984). Experiential learning: Experience as the source of learning and development. Upper Saddle River, NJ: Prentice Hall. Retrieved January 10, 2020, from http://academic.regis.edu/ed205/Kolb.pdf 
Lenth, R. (2019). emmeans: Estimated Marginal Means, aka Least-Squares Means ( $R$ Package Version 1.4). Retrieved December 21, 2020, from https://cran.r-project.org/package=emmeans

Lewis, M. D., \& Granic, I. (2000). Introduction: A new approach to the study of emotional development. In Lewis, M. D., \& Granic, I. (Eds.), Emotion, development, and self-organization: Dynamic systems approaches to emotional development (pp. 1-15). Cambridge: Cambridge University Press.

Linnenbrink-Garcia, L., Durik, A. M., Conley, A. M., Barron, K. E., Tauer, J. M. Karabenick, S. A., \& Harackiewicz, J. M. (2010). Measuring situational interest in academic domains. Educational and Psychological Measurement, 70(4). 1177/0013164409355699.

Lyvers-Peffer, P. A. (2011). Demographics of an undergraduate animal sciences course and influence of gender and major on course performance. NACTA Journal, 55, 26-31.

Makowski, D., Ben-Shachar, M. S., Patil, I., \& Lüdecke, D. (2019). Methods and algorithms for correlation analysis in R. Journal of Open Source Software, 5(51), 2306. 10.21105/joss.02306

Markus, H. R., \& Kitayama, S. (1994). The cultural construction of self and emotion: Implications for social behavior. In Kitayama, S., \& Markus, H. R (Eds.), Emotion and culture: Empirical studies of mutual influence (pp. 89-130). Washington, DC: American Psychological Association. https:// doi.org/10.1037/10152-003

Marton, F., \& Säljö, R. (1976). On qualitative differences in learning: I. Outcome and process. British Journal of Educational Psychology, 46(1), 411. https://doi.org/10.1111/j.2044-8279.1976.tb02980.x

McWhaw, K., \& Abrami, P. C. (2001). Student goal orientation and interest: Effects on students' use of self-regulated learning strategies. Contemporary Educational Psychology, 26(3), 311-329. https://doi.org/10.1006/ ceps.2000.1054

Pintrich, P. R., \& Schrauben, B. (1992). Students' motivational beliefs and their cognitive engagement in classroom academic tasks. In Schunk, D. H., \& Meece, J. L. (Eds.), Student perceptions in the classroom (pp. 149-183). Mahwah, NJ: Erlbaum.

Pintrich, P. R., \& Schunk, D. H. (1996). Motivation in education: Theory, research and applications. Upper Saddle River, NJ: Prentice-Hall.

Posey, R. D., Hoffsis, G. F., Cullor, J. S., Naylor, J. M., Chaddock, M., \& Ames T. R. (2012). Preparing students for careers in food-supply veterinary medicine: A review of educational programs in the United States. Journal of Veterinary Medical Education, 39(3), 257-262. https://doi.org/10.3138/ jvme.0112-012R

Priniski, S. J., Hecht, C. A., \& Harackiewicz, J. M. (2018). Making learning personally meaningful: A new framework for relevance research. Journal of Experimental Education, 86(1), 11-29. https://doi.org/10.s1080/ 00220973.2017 .1380589

Priniski, S. J., Rosenzweig, E. Q., Canning, E. A., Hecht, C. A., Tibbetts, Y., Hyde, J. S., \& Harackiewicz, J. M. (2019). The benefits of combining value for the self and others in utility-value interventions. Journal of Educational Psychology, 111(8). https://doi.org/10.1037/edu0000343

R Core Team. (2019). R: A language and environment for statistical computing. Vienna, Austria: R Foundation for Statistical Computing. Retrieved April 10, 2020, from www.r-project.org/

Reiling, B. A., Marshall, T. T., Brendemuhl, J. H., McQuagge, J. A., \& Umphrey, J. E. (2003). Experiential learning in the animal sciences: Development of a multispecies large-animal management and production practicum. Journal of Animal Science, 81(12), 3202-3210. https://doi.org/ 10.2527/2003.81123202x

Rosenzweig, E. Q., Harackiewicz, J. M., Priniski, S. J., Hecht, C. A., Canning E. A., Tibbetts, Y., \& Hyde, J. S. (2019). Choose your own intervention: Using choice to enhance the effectiveness of a utility-value intervention. Motivation Science, 5(3), 269-276. https://doi.org/10.1037/mot0000113
Rosenzweig, E. Q., \& Wigfield, A. (2016). STEM motivation interventions for adolescents: A promising start, but further to go. Educational Psychologist, 51( 2), 146-163. https://doi.org/10.1080/00461520.2016.1154792

Rosenzweig, E. Q., Wigfield, A., \& Hulleman, C. S. (2020). More useful or not so bad? Examining the effects of utility value and cost reduction interventions in college physics. Journal of Educational Psychology, 112(1) 166-182. https://doi.org/10.1037/edu0000370

Rotgans, J. I., \& Schmidt, H. G. (2011). Cognitive engagement in the problem-based learning classroom. Advances in Health Sciences Education, 16(4), 465-479. https://doi.org/10.1007/s10459-011-9272-9

Rotgans, J. I., \& Schmidt, H. G. (2014). Situational interest and learning: Thirst for knowledge. Learning and Instruction, 32, 37-50. https://doi. org/10.1016/j.learninstruc.2014.01.002

Rozek, C. S., Svoboda, R. C., Harackiewicz, J. M., Hulleman, C. S., \& Hyde, J. S. (2017). Utility-value intervention with parents increases students' STEM preparation and career pursuit. Proceedings of the National Academy of Sciences USA, 114(5), 909-914. https://doi.org/10.1073/pnas.1607386114

Sandars, J. (2009). The use of reflection in medical education: AMEE Guide No. 44. Medical Teacher, 31(8), 685-695. https://doi.org/10.1080/ 01421590903050374

Schiefele, U. (2009). Situational and individual interest. In Wenzel, K. R., \& Wigfield, A. (Eds.), Educational psychology handbook series, Handbook of motivation at school (pp. 197-222). New York, NY: Routledge/Taylor \& Francis Group.

Schiefele, U., Krapp, A., \& Winteler, A. (1992). Interest as a predictor of academic achievement: A meta-analysis of research. In Renninger, K. A. Hidi, S., \& Krapp, A. (Eds.), The role of interest in learning and development (pp. 183-212). Hillsdale, NJ: Erlbaum.

Schraw, G., \& Lehman, S. (2001). Situational interest: A review of the literature and directions for future research. Educational Psychology Review, 13(1), 23-52. https://doi.org/10.1023/A:1009004801455

Shenton, A. K. (2004). Strategies for ensuring trustworthiness in qualitative research projects. Education for Information, 22(2), 63-75. https://doi org/10.3233/EFI-2004-22201

Silverman, D. (2001). Interpreting qualitative data: Methods for analyzing talk, text and interaction (2nd ed.). London: Sage.

Suresh, K. (2011). An overview of randomization techniques: An unbiased assessment of outcome. Clinical Research, 4, 8-11. https://doi.org/ 10.4103/0974-1208.82352

Taylor, B., Henshall, C., Kenyon, S., Litchfield, I., \& Greenfield, S. (2018). Can rapid approaches to qualitative analysis deliver timely, valid findings to clinical leaders? A mixed methods study comparing rapid and thematic analysis. BMJ Open, 8, 10. https://doi.org/10.1136/bmjopen-2017 $-019993$

Twisk, J., de Boer, M., de Vente, W., \& Heymans, M. (2013). Multiple imputation of missing values was not necessary before performing a longitudinal mixed-model analysis. Journal of Clinical Epidemiology, 66(9), 1022 1028. https://doi.org/https://doi.org/10.1016/j.jclinepi.2013.03.017

Ulriksen, L. (2009). The implied student. Studies in Higher Education, 34(5), 517-532. https://doi.org/10.1080/03075070802597135

West, B. T., Welch, K. B., \& Galecki, A. T. (2014). Linear mixed models: A practical guide using statistical software. New York, NY: Chapman and Hall/ CRC Press. https://doi.org/10.1201/b17198

Witherington, D. C., \& Crichton, J. A. (2007). Frameworks for understanding emotions and their development: Functionalist and dynamic systems approaches. Emotion, 7(3), 628-637. https://doi.org/10.1037/1528-3542.7.3.628

Wong, B., \& Chiu, Y. L. T. (2018). University lecturers' construction of the "ideal" undergraduate student. Journal of Further and Higher Education, 44(1), 54-68. https://doi.org/10.1080/0309877X.2018.1504010 